Volume 2 número 15, 2013

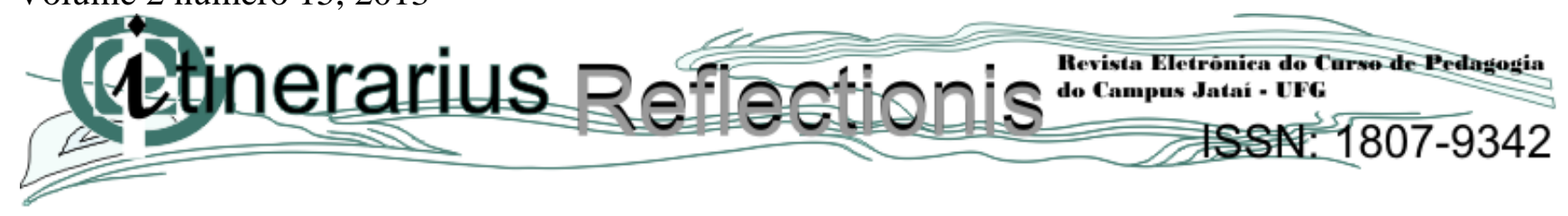

\title{
USO DE ATIVIDADES PRÁTICAS NO ENSINO DE QUÍMICA EM UMA ESCOLA PÚBLICA DE JATAÍ-GOIÁS
}

\begin{abstract}
Danielle Silva Lima - Instituto Federal de Goiás /Câmpus Jataí; danielle.lima0@ hotmail.com Carlos Cézar da Silva - Instituto Federal de Goiás /Câmpus Jataí; ccezas@ gmail.com.
\end{abstract}

RESUMO: Este estudo visou inserir a experimentação nas aulas de Tópicos de Química como uma metodologia alternativa para o ensino de Química. A pesquisa foi realizada com os alunos dos $2^{\circ}$ séries do Ensino Médio do Colégio Estadual João Roberto Moreira, Jataí-GO, usando-se o suporte do delineamento experimental, no qual foram realizadas duas aulas práticas que abordavam o conteúdo reações químicas. A coleta de dados foi obtida através de imagens (fotos registradas) e questionário. Os alunos demonstraram uma dificuldade em classificar substâncias e reconhecer as evidências de reações químicas. As atividades experimentais mostraram-se eficientes, porém ao utilizar as mesmas em turmas diferentes, percebe-se uma variação significativa na aprendizagem dos alunos.

Palavras-Chave: Experimentação; Tópicos de Química; Classificação das Reações.

\begin{abstract}
This study aimed to insert the trial in the classes of Topics in Chemistry as an alternative methodology for the teaching of chemistry. The survey was conducted with students of the 2 nd series of High School in the College Joao Roberto Moreira, Jatai-GO, using the support of the experimental design, in which two classes that addressed content chemical reactions were realized. The data collection was obtained through images (pictures recorded) and questionnaire. The results showed that students demonstrated a difficulty in classifying substances and recognizing the evidences of chemical reactions. The experimental activities were effective, but when using the same activities in different classes, it is notable a significant variation on student learning.
\end{abstract}

Key-words: Experimentation; Topics in Chemistry; Classification of Reactions. 


\section{INTRODUÇÃO}

A escola tem um papel fundamental na educação no sentindo de desenvolver competências básicas integradas com os saberes disciplinares, que facilite ao seu público o exercício pleno de cidadão e possibilite assegurar que todos os indivíduos desenvolvam e ampliem suas capacidades, diminuindo assim a exclusão social. De acordo com Mesquita \& Medeiros (2006) a promoção do conhecimento e a formação de cidadãos comprometidos com os princípios sociais têm quebrado paradigmas, visando incorporar ao ensino, atividades que promovam o desenvolvimento de habilidades necessárias às práticas educacionais da atualidade.

Particularmente, no ensino de Química, isso se tornará possível se houver uma mudança na visão que os professores têm desta ciência, possibilitando assim novas práticas pedagógicas. Nessa perspectiva, o professor deve assumir uma postura crítica e ética, ser um agente de mudanças e adquirir novas ideias. Segundo Perrenoud (1999, 2000 e 2002), a competência é a faculdade de mobilizar e associar um conjunto de recursos ou esquemas mentais (ações ou operações mentais) de caráter cognitivo, sócio-afetivo e psicomotor (saberes teóricos e da experiência e a afetividade) para solucionar com pertinência e eficácia uma série de situações novas.

No ensino de Ciências, a utilização de metodologias no processo de ensino-aprendizagem (baseado somente em quadro, giz e livro didático), muitas vezes é criticado, pois se acredita que este tipo de ensino refere-se a uma ação passiva do aluno que frequentemente é tratado como mero ouvinte das informações que o professor expõe, isto tende a fazer com que o mesmo memorize o conteúdo no qual, na maioria das vezes, este não compreenda o conceito. Para o ensino de Ciências visando uma aprendizagem significativa, é necessário despertar no estudante o interesse para a compreensão do mundo em que vive, possibilitando o desenvolvimento do senso crítico e do espírito investigativo. É importante que o jovem reconheça o valor da ciência, e através dela busque novas informações pra si. Para tanto, faz-se necessário que a Ciência seja ensinada de forma inovadora, problematizada, contextualizada e significativa para o aprendiz. Segundo SANTOS et. al. (2004): 


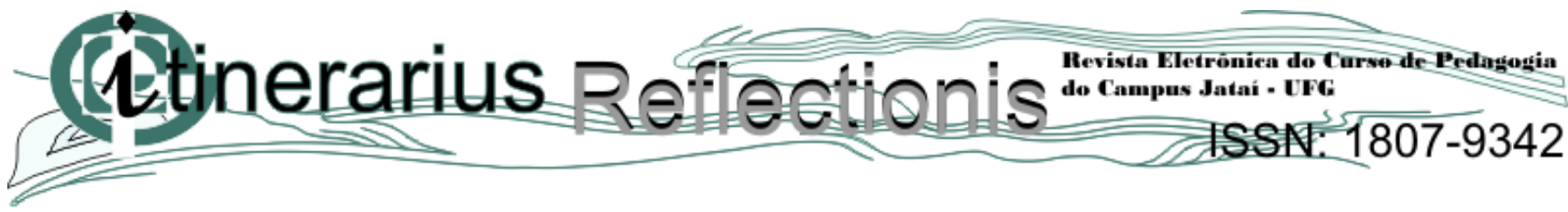

As propostas mais inerentes, para o ensino de Química, têm como um dos pressupostos a necessidade do envolvimento ativo dos alunos nas aulas, em um processo interativo, professoraluno, em que as concepções conceituais dos alunos sejam contempladas. Isso significa criar oportunidades para que eles expressem como vêem o mundo, como entendem os conceitos, quais são as suas dificuldades.

Na educação sabe-se que o papel do professor é de grande importância, especificamente nas aulas de Química, se a aula não é bem planejada e conduzida, o aluno não consegue compreender os conceitos desta ciência, que assim se se tornam abstratos. É sabido que cabe ao professor ser mediador na produção de conhecimento, administrar a aula, promovendo a produção de saberes, afinal ser professor é educar, por isto ele é um sujeito, assim como aluno deste processo sabe-se também que as ações deste profissional são limitadas por não disporem tempo para o planejamento de suas aulas, pela escassez de recursos materiais e pela carga horária insuficiente (CARDOSO \& COLINVAUX, 2000).

O aprendizado da Química depende também de outras variáveis, como: aluno, recursos didáticos, ambiente sócio-cultural ao qual estão inseridos e da abordagem desta área do conhecimento.

Segundo ARROIO (2006) et. al.,

(...) verifica-se a necessidade da utilização de formas alternativas relacionadas ao ensino de química, com o intuito de despertar o interesse e a importância dos conceitos químicos presentes nos currículos escolares.

Como forma de melhorar a assimilação e consequentemente a aprendizagem, propõe-se a aplicação de metodologias alternativas para o ensino de química que possam inserir professores e alunos numa discussão "no que diz respeito às relações entre ciência, tecnologia, sociedade e ambiente" (SILVA \& OLIVEIRA, 2008). Sendo assim, a experimentação seria uma boa estratégia para solucionar este problema, no qual permite articular teoria e prática. A importância da inclusão da experimentação está na caracterização de seu papel investigativo e de sua função pedagógica em auxiliar o aluno na compreensão dos fenômenos químicos (SANTOS \& SCHNETZLER, 1996). O uso do laboratório pode estimular a aprendizagem dos alunos e possibilitar uma melhor compreensão dos conteúdos trabalhos em sala de sala.

Quando a experimentação é bem conduzida e estruturada em bases epistemológicas claras, a mesma surge como exercício imprescindível na atividade docente em Química. Ao utilizar a experimentação durante as aulas de ciências/química, associando os conteúdos curriculares ao que o educando vivenciou, o educador trabalhará de forma mais contextualizada, visando assim à formação de cidadãos mais críticos e ativos na sociedade. Segundo DEMO (1999), a contextualização significa a vinculação com a vida do aluno, 
bem como com as suas potencialidades. Assim, a contextualização é essencial para que todo o trabalho desenvolvido não tenha um caráter apenas ilustrativo, e cabe ao professor direcionar o aluno.

No ensino da Química, a experimentação é a atividade didático-pedagógica que mais desperta o interesse e a curiosidade dos aprendizes. Lima et al. (2007) dizem que os experimentos demonstrativos ajudam a focar atenção do estudante nos comportamentos e propriedades de substâncias químicas.

Muitos professores consideram importante a utilização dessa prática durante as aulas, tendo em vista o caráter investigativo da ciência e da disciplina de Química. Para GIORDAN (2003) “A experimentação desperta forte interesse entre os alunos proporcionando um caráter motivador, lúdico, essencialmente vinculado aos sentidos. As atividades experimentais possibilitam que o aluno construa seu conhecimento".

Por outro lado, ao tentar executar aulas experimentais no Ensino Médio, mais precisamente em escolas de menor poder aquisitivo, o professor de Química se depara com uma série de problemas. De acordo com Lima (2004), os docentes alegam um grande número de obstáculos como a falta de estrutura física das escolas, material didático, número reduzido de aulas, excesso de alunos por sala, como também a necessidade de auxiliares para ajudar na organização das aulas laboratoriais, o que os impedem na maioria das vezes de realizarem atividades experimentais. Isso também pode ser confirmado por Machado e Mól (2008) "a utilização de laboratórios escolares exige cuidados especiais por diversos aspectos entre os quais são salientados: inadequação do ambiente, grande número de alunos em sala, inexperiência e agitação típica de adolescentes".

Diante desses problemas, professores de Química e Ciências, de modo geral, mostram-se insatisfeitos com a infraestrutura de suas escolas, principalmente aqueles que atuam em escolas públicas de cunho Estadual ou Municipal. Arruda e Laburu (2001) mencionam que a ausência de aulas experimentais é frequentemente apontada pelos professores como uma das principais deficiências no ensino das disciplinas científicas nos Ensinos Fundamental e Médio, por diversas razões já bem conhecidas, tais como: falta de laboratórios e equipamentos nos estabelecimentos de ensino; número excessivo de aulas o que impede uma preparação adequada de aulas práticas; desvalorização das atividades experimentais; ausência de professores designados para laboratório; formação insuficiente do professor, principalmente entre os licenciados em Ciências Naturais e Biologia.

Conforme GIORDAN (1999) as tentativas de se incluir as atividades experimentais no currículo escolar já vêm se arrastando a algumas décadas, porém, essas tentativas não têm conseguido grandes sucessos, sendo quase sempre um fracasso. Os "kits" experimentais são bons exemplos desse tipo de 
tentativa, pois estes estão sendo empilhados nos laboratórios, na maioria das vezes não são utilizados nas aulas práticas, e assim acabam se tornando entulhos em algumas escolas públicas (GIOPPO; SCHEFFER; NEVES, 1999).

Ao invés de se limitar com críticas ao não funcionamento e realização de atividades experimentais, como as que apresentamos até então, este trabalho se situa ao lado daqueles que se preocupam em apontar possibilidades para o desenvolvimento destas atividades em instituições públicas. Desse modo, é importante que os professores de Química e Ciências, juntamente com a gestão escolar, comecem a mudar suas visões em relação ao planejamento e desenvolvimento de atividades experimentais nas escolas.

De acordo com Araújo e Abib (2003), para que os professores possam lograr sucesso em sua prática pedagógica, acredita-se ser um imperativo que a metodologia experimental adotada seja selecionada tendo em vista quais são os principais objetivos a serem alcançados com a mesma, uma vez que as diferentes modalidades de experimentação tendem a priorizar e facilitar o alcance de diferentes objetivos educacionais, cabendo, portanto, a quem conduzirá a atividade a escolha mais adequada da mesma, considerando o momento, o contexto e as finalidades pretendidas.

Portanto, a química no ensino médio não pode ser ensinada como um fim em si mesmo, senão estaremos fugindo do objetivo maior da educação básica, que é assegurar ao individuo uma boa formação e participação na sociedade (SANTOS e SCHNETZLER, 2003). Segundo Vasconcelos (2001), citado por LIMA e MARCONDES, 2005, “a mudança da prática vem aos poucos, não porque assim se deseje, mas por não se conseguir mudá-la de uma vez em decorrência de todo o seu enraizamento subjetivo e objetivo". E é nesse enfoque, que acreditamos que com a realização deste trabalho no âmbito escolar, a experimentação promoverá a apreensão pessoal dos significados, favorecendo o desenvolvimento da curiosidade epistemológica, que é indispensável para a aprendizagem crítica dos alunos. Assim, no caso da Química, a experimentação é essencial na aprendizagem, no qual possibilita desenvolver conteúdos conceituais e procedimentais que os PCN's preveem.

Na tentativa de amenizar os problemas das escolas públicas em relação à dificuldade dos alunos no ensino da Química, a Secretária da Educação do Estado de Goiás (SEDUC/GO), após realizar um diagnóstico sobre a realidade do ensino nas escolas públicas de Goiás, publicou em 2011 as diretrizes curriculares para o ensino de química (Diretrizes, SEDUC/GO, 2011). Essas diretrizes foram elaboradas por profissionais ligados a esta secretária e abordam pontos fundamentais tais como: currículo flexível, metodologias diferenciadas, ensino por situações-problemas, experimentação, contextualização e interdisciplinaridade. Desta forma, as escolas públicas passaram a ter certa liberdade para escolher 
disciplinas alternativas que seriam trabalhadas com o intuito de melhorar o ensino das disciplinas mais críticas de cada escola. Sendo assim, surgiu a disciplina de Tópicos de Química na turma de 2o ano, no qual desenvolvemos o projeto de pesquisa.

Dessa forma, este estudo teve como objetivos utilizar e avaliar a experimentação nas aulas de Tópicos de Química, para as séries do $2^{\circ}$ do Ensino Médio do Colégio Estadual João Roberto Moreira, como uma metodologia alternativa e analisar a influência de metodologias alternativas no ensino de química.

\section{METODOLOGIA}

Para efetivação da pesquisa utilizou-se de métodos de abordagem e métodos de procedimento, no qual os resultados foram avaliados quantitativamente baseando-se em questionários com perguntas fechadas que abordavam conceitos teóricos trabalhados em sala de aula. A pesquisa foi realizada com os alunos do Ensino Médio do Colégio Estadual João Roberto Moreira, Jataí-GO, usando-se o suporte do delineamento experimental, no qual foram aplicados um total de duas aulas práticas que abordavam o conteúdo Reações Químicas. Essas aulas práticas foram aplicadas na disciplina alternativa Tópicos de Química, com aproximadamente 80 alunos da $2^{\mathrm{a}}$ série $(\mathrm{A}, \mathrm{B}$ e $\mathrm{C}$ ). Os experimentos foram conduzidos no próprio laboratório de Ciências da instituição, no mês de maio do ano letivo de 2013.

A pesquisa teve início com a escolha das turmas e os conteúdos que seriam ensinados. Por ser uma disciplina alternativa e extracurricular a escolha dos conteúdos fica a critério do próprio professor, não tendo assim uma matriz oficial curricular. Sabendo que os conteúdos de Química do Ensino Médio são trabalhados rapidamente, e alguns outros nem são vistos, devido ao insuficiente número de aulas semanais, a disciplina Tópicos de Química veio como uma alternativa para que ocorra uma mudança nessa situação, contribuindo assim para uma melhor aprendizagem dos alunos. Esta disciplina é oferecida aos alunos das $2^{\mathrm{a}}$ séries da instituição, por ser tratar de uma série em que os conteúdos são em maior número e mais extensos.

As aulas práticas foram organizadas por meio de roteiros (Anexos 1 e 2), no qual continham o procedimento experimental e algumas questões. As turmas foram levadas para o laboratório em momentos diferentes, os alunos divididos em grupos de quatro a cinco pessoas, utilizando-se as bancadas para realizar os experimentos. Ao final de cada aula prática, os roteiros contendo os questionários foram entregues aos alunos, como um método de avaliação da mesma. Um questionário foi aplicado aos grupos de alunos para se obter dados passíveis a serem analisados posteriormente, observando-se as opiniões e concepções dos mesmos a cerca da metodologia alternativa adotada, da disciplina de Tópicos de Química, da sua aprendizagem e do seu aproveitamento entre outros. 


\section{RESULTADOS E DISCUSSÃO}

A avaliação das respostas questionadas nas aulas propostas foi pautada em variáveis quantitativas a partir de critérios conceituais teóricos que estabeleciam uma relação percentual ao dado exposto e respondido. A primeira aula prática possuía um questionário contendo quatro perguntas. As respostas das três primeiras foram avaliadas em satisfatória, parcialmente satisfatória e insatisfatória. Já a última era uma questão subjetiva contendo respostas pessoais, ganhando assim uma análise mais profunda e detalhada.

A resposta satisfatória teria uma avaliação de $100 \%$ de aproveitamento, enquanto a resposta parcialmente satisfatória e insatisfatória seria avaliada em valores abaixo de $100 \%$.

A primeira aula prática executada no dia 02 de maio de 2013 foi a CLASSIFICAÇÃO DAS REAÇÕES: ADIÇÃO E DECOMPOSIÇÃO conforme o ANEXO - 1. Participaram desta prática, três $2^{\mathrm{a}}$ série (A, B e C), sendo um total de 77 alunos, os quais ao término das aulas responderam as questões do roteiro.

O conteúdo teórico explorado tem por finalidade trabalhar as classificações de uma reação química, abordando especificamente reações de adição ou síntese, e decomposição ou análise.

Todas as questões foram analisadas de acordo com o rendimento de cada turma. Cada turma foi dividida em grupos, contendo aproximadamente de quatro a cinco alunos por grupo. No $2^{\text {a }}$ série A (25 alunos), a turma foi dividida em sete grupos, no qual continham 4 grupos formados por 4 alunos e 3 grupos formados por 3 alunos. Já a $2^{\text {a }}$ série B e C (26 alunos), foram divididos em cinco grupos, formados por 4 grupos de 5 alunos e apenas 1 grupo de 6 alunos.

Ao analisarmos a $2^{\mathrm{a}}$ série $\mathrm{A}$, no que diz respeito à primeira questão "Quais os conceitos e conteúdos de química elou ciências podem ser explorados com esta atividade?" os grupos responderam de forma satisfatória, sendo alcançados $100 \%$ do objetivo esperado. A $2^{\mathrm{a}}$ série B, $80 \%$ responderam de forma satisfatória e $20 \%$ responderam de forma incompleta e insatisfatória. Já a $2^{\text {a }}$ série C, $60 \%$ acertaram e $40 \%$ responderam de forma incompleta e insatisfatória. Sendo assim, podemos pressupor que embora foram relacionados alguns conceitos e conteúdos na resposta da atividade, alguns grupos, poderiam ter explorado mais suas respostas, estendendo ou melhorando as mesmas.

Na segunda questão "Dê o nome das reações químicas (classificação) envolvidas na experiência." verificamos que $2^{\mathrm{a}}$ série $\mathrm{A}, 86 \%$ dos alunos acertaram, porém os outros $14 \%$ se equivocaram na resposta, e 


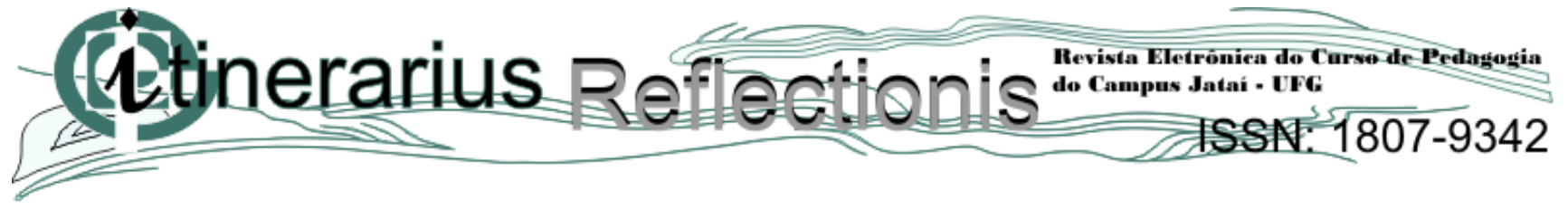

descreveram os nomes dos reagentes e produtos das reações químicas. A $2^{\mathrm{a}}$ série B, 60\% acertaram, 20\% erraram e os outros $20 \%$ responderam de forma incompleta. Pode-se dizer que essa questão evidencia novamente a dificuldade de alguns alunos em classificar as reações. Por último, a turma do $2^{\circ}$ ano $\mathrm{C}$ alcançou $100 \%$ de aproveitamento nas respostas, teve assim um resultado bem satisfatório.

Na terceira questão "Qual foi à relevância no seu aprendizado ao realizar esta experiência?”, ao preparar esta questão um padrão de respostas era esperado. Analisando a $2^{\mathrm{a}}$ série A, $86 \%$ responderam de maneira satisfatória, porém 14\% responderam insatisfatoriamente, não alcançando o objetivo esperado. Já a $2^{\mathrm{a}}$ série $\mathrm{B}$ e $\mathrm{C}$, todos os grupos responderam de maneira correta, alcançando assim os $100 \%$.

A última questão “Em sua opinião, aulas práticas que envolvam a teoria trabalhada em sala de aula desenvolvem melhor o seu conhecimento de química? ( ) Sim

( ) Não Justifique." verificamos que de maneira geral os alunos marcaram que "sim". Logo abaixo, temos as respostas de 3 grupos, sendo um grupo de cada turma, e assim chamaremos de A, B, e C respectivamente:

\section{Grupo A}

"Sim. Com a aula prática podemos saber melhor sobre o conteúdo trabalhado, e assim tendo um conhecimento melhor de como fazer as experiências, conhecendo assim os produtos utilizados e suas transformações."

\section{Grupo B}

"Sim. Porque, quando só escutamos a professora falando não temos muito como imaginar, e quando vemos a experiência achamos interessante e observamos como as reações se transformam em uma experiência."

\section{Grupo C}

"Sim. Porque não estamos acostumados com esse tipo de aula, e isso nos faz prestar mais atenção nas aulas, e conseguimos aprender e nos adaptar melhor ao conteúdo."

A segunda aula prática executada no dia 23 de maio de 2013 também foi a CLASSIFICAÇÃO DAS REAÇÕES: SIMPLES TROCA E DUPLA-TROCA conforme o ANEXO - 2. Esta aula prática foi conduzida e analisada da mesma maneira que a primeira, e o número de alunos também foi o mesmo. 


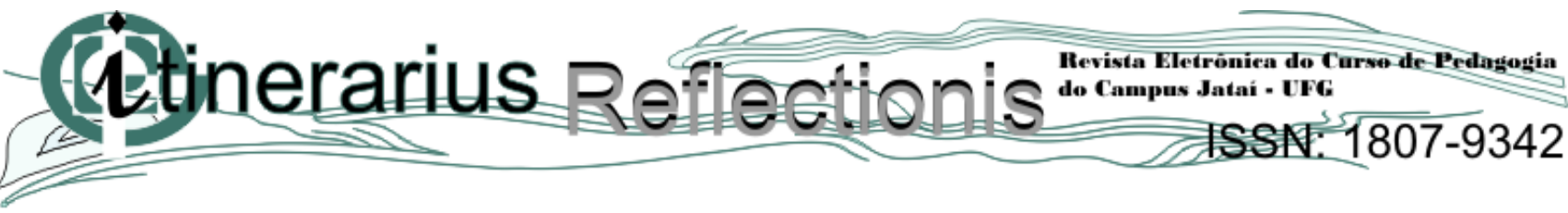

Esta aula prática, também teve como objetivo trabalhar as classificações de uma reação química, abordando especificamente reações de simples troca e dupla troca.

Ao analisarmos a $2^{\mathrm{a}}$ série $\mathrm{A}$, verificamos que ao responderem a primeira questão "Dê o nome das reações químicas (classificação) envolvidas na experiência”, 40\% dos alunos acertaram 40\% erraram e $20 \%$ acertaram parcialmente a questão, ou seja, observou-se que as reações de simples troca e dupla troca exigem um grau de abstração maior por parte dos alunos, diferentemente das reações de síntese e decomposição. Já a $2^{\mathrm{a}}$ série B e C $100 \%$ dos alunos acertaram a questão, demonstrando uma maior facilidade na interpretação da mesma.

Na segunda questão “O ser humano em seu cotidiano pode se deparar com vários tipos de reações químicas. Um tipo de reação inorgânica muito importante em nosso cotidiano é a reação de simples troca, ou de deslocamento, ou ainda, de substituição, no qual ocorrem quando uma substância simples reage com uma substância composta, originando uma nova substância simples e outra composta. Ocorre uma troca de seus elementos ligantes, daí a origem de seu nome. Diante disso, responda: O que são substâncias simples e compostas? Justifique com exemplos", ao analisarmos as respostas dos alunos da $2^{\mathrm{a}}$ série A, $60 \%$ acertaram e $40 \%$ responderam insatisfatoriamente. A $2^{\mathrm{a}}$ série B, $25 \%$ erraram e $75 \%$ responderam insatisfatoriamente. Por último, a $2^{\mathrm{a}}$ série C, $80 \%$ acertaram e $20 \%$ responderam, mas de forma incompleta. De acordo com os resultados, percebemos que ao responderem essa questão, os grupos demonstraram dúvidas ao descreverem o conceito de substâncias simples e compostas. Além disso, os mesmos não citaram exemplos em suas respostas.

$\mathrm{Na}$ terceira questão "Em uma equação química, o balanceamento tem um papel fundamental, pois consiste em igualar o número de elementos do produto com os reagentes. Sendo assim, verifique o balanceamento das equações químicas acima, e faça o balanceamento se for necessário”, verificamos que a $2^{\mathrm{a}}$ série A e C conseguiram responder a questão corretamente, tendo assim um aproveitamento de $100 \%$. Portanto, pode-se concluir que este conteúdo foi bem assimilado pelos alunos. Já a $2^{\text {a }}$ série B 50\% dos alunos acertaram, $25 \%$ não responderam e os outros $25 \%$ responderam insatisfatoriamente, pois efetuaram o balanceamento apenas da reação 1 (simples troca), deixando assim a reação 2 (dupla troca), sem balancear.

A quarta questão "Ao analisar a reação de dupla troca ou reação de metátese (reação onde há dois reagentes, ambos compostos gerando dois produtos, sendo que são igualmente dois compostos, permutando entre si dois elementos ou radicais) realizada durante a aula prática, descreva o seu produto final", verificarmos que na $2^{\mathrm{a}}$ série $\mathrm{A}, 60 \%$ dos alunos acertaram a questão e $40 \%$ responderam 


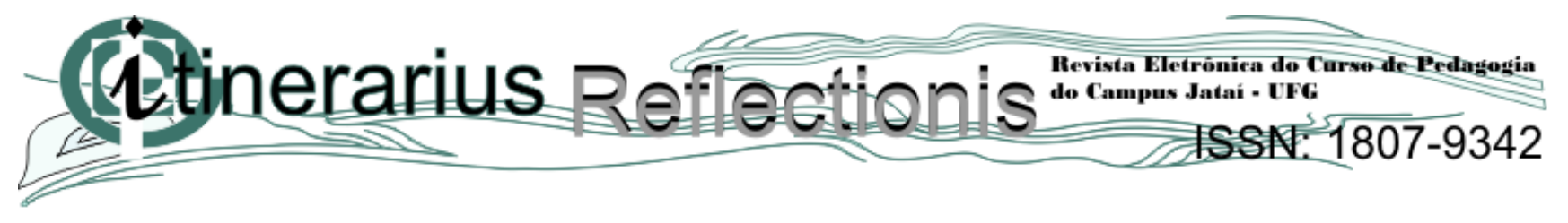

incorretamente. A $2^{\mathrm{a}}$ série B 50\% acertaram e 50\% responderam insatisfatoriamente. E por último, temos a $2^{a}$ série C, no qual $40 \%$ acertaram $40 \%$ erraram e $20 \%$ responderam insatisfatoriamente. Com esses resultados, pode-se dizer que alguns grupos encontraram dificuldade em descrever as evidências de uma reação química. Dessa maneira, pode-se pressupor que os alunos não tiveram uma interpretação clara na pergunta, respondendo assim de forma equivocada.

A quinta e última questão "A experimentação é a atividade didático-pedagógica que mais desperta o interesse e a curiosidade dos aprendizes. (GIORDAN,2003).Você concorda com essa afirmação? ( ) SIM ( ) NÃO Justifique sua resposta.", verificamos que de maneira geral os alunos marcaram que "sim". Em seguida, também temos as respostas de 3 grupos, sendo um grupo de cada turma, e assim chamaremos de A, $\mathrm{B}$, e $\mathrm{C}$ respectivamente:

\section{Grupo A}

"Porque é através da aula prática em si, que presenciamos de fato o que ocorrera nas experiências especificamente voltadas ao conteúdo estudado de Química. Despertando-nos mais interesse e curiosidade em aprender."

\section{Grupo B}

"Concordamos pois as atividades práticas são um complemento das atividades teóricas, assim deixando as aulas mais dinamizadas, e até mais divertidas para os alunos e professor."

\section{Grupo C}

"Sim, pois interage melhor com os alunos e com a turma ajudando-nos e assim nós ficamos mais interessados e achamos esse tipo de aula mais divertido e aprendemos mais."

Considerando as respostas e as ações dos alunos observadas durante a aplicação do questionário e da atividade em geral, pode-se afirmar que uma aula prática possuem algumas vantagens. Os alunos demostraram interesse durante as atividades, despertando assim a curiosidade e atenção dos mesmos (figura 1 e 2). Essas aulas podem ser consideradas como uma alternativa para aqueles educadores de Ensino Médio que procuram diversificar suas aulas, melhorando a transmissão do conteúdo químico. 


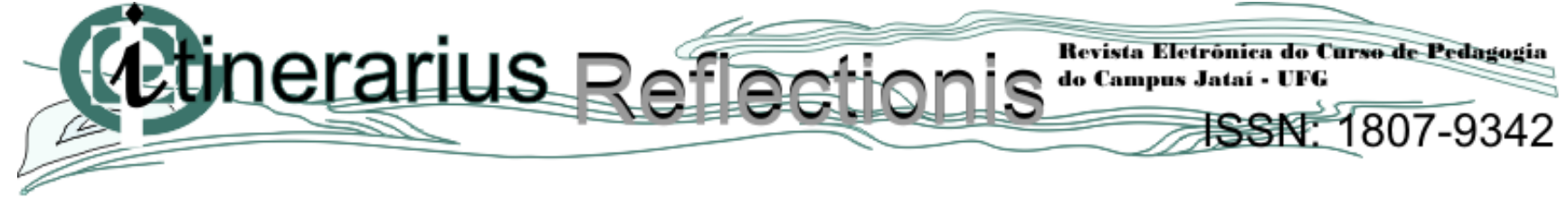
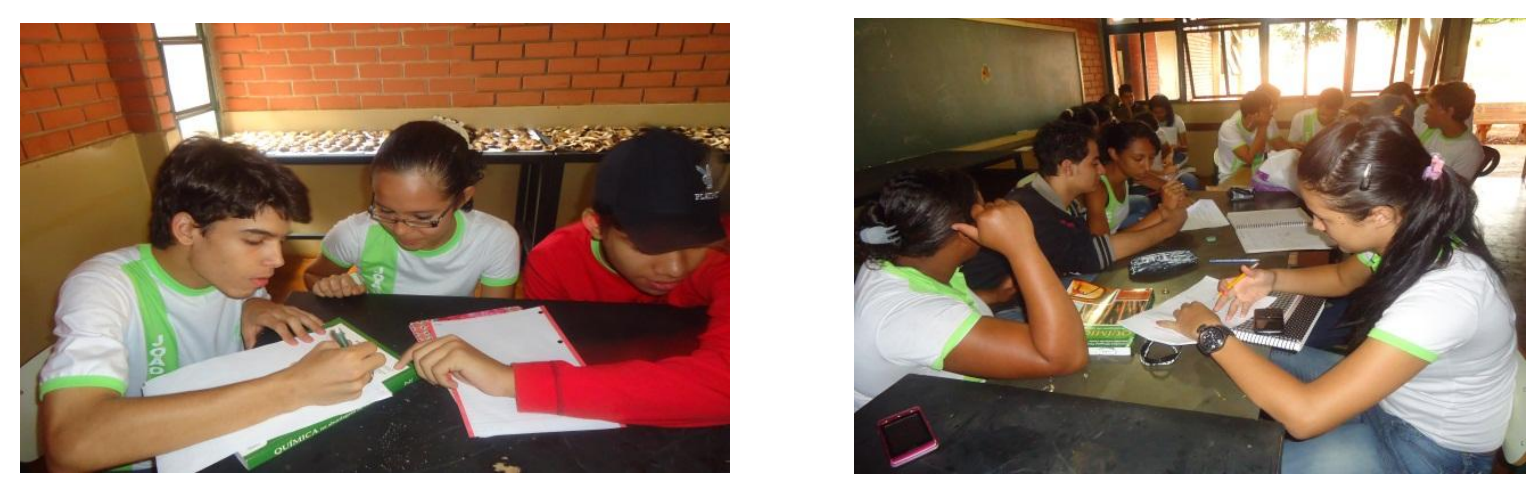

Figura 1 e 2 - Participação dos alunos durante a aplicação dos questionários das aulas práticas.

\section{CONCLUSÃO}

A inserção de experimentação no ensino de Química no Colégio Estadual João Roberto Moreira nas aulas de Tópicos de Química para as $2^{\text {a }}$ séries do Ensino Médio, como uma metodologia alternativa mostrou-se eficiente de forma geral, porém ao utilizar as mesmas atividades em turmas diferentes, percebemos uma variação significativa na aprendizagem dos alunos, no qual alguns demostraram dificuldades ao compreender e responder algumas questões relacionadas ao conteúdo proposto.

No que diz respeito ao tema classificação de reações químicas, percebeu-se que há uma dificuldade por parte de alguns alunos em reconhecer substâncias simples e compostas, especificar simples troca e dupla troca, além da dificuldade em perceber as evidências de uma reação química.

Os alunos quando questionados sobre a inserção de atividades experimentais após as aulas teóricas de classificação de reações químicas, evidenciaram a importância do professor em apresentar novas metodologias e a possibilidade do contato com os materiais e reagentes. Além disso, demonstraram maior interesse pelas aulas devido às mesmas serem mais dinâmicas, divertidas e promoverem uma maior interação entre os alunos e o professor. As atividades exigiram uma participação ativa dos estudantes nos processo de aprendizagem, havendo entre os alunos a troca de informação e a renovação de novos conceitos.

Após a execução da pesquisa, percebeu-se que a inclusão de atividades experimentais deve ser mais utilizada como metodologia nas aulas de Química, devendo ser implementada de forma mais frequente nas turmas de Ensino Médio das escolas públicas. Essas aulas podem ser consideradas como uma alternativa para aqueles educadores de Ensino Médio que procuram diversificar suas aulas, melhorando a transmissão do conteúdo químico, formando assim cidadãos mais críticos e ativos na sociedade. 


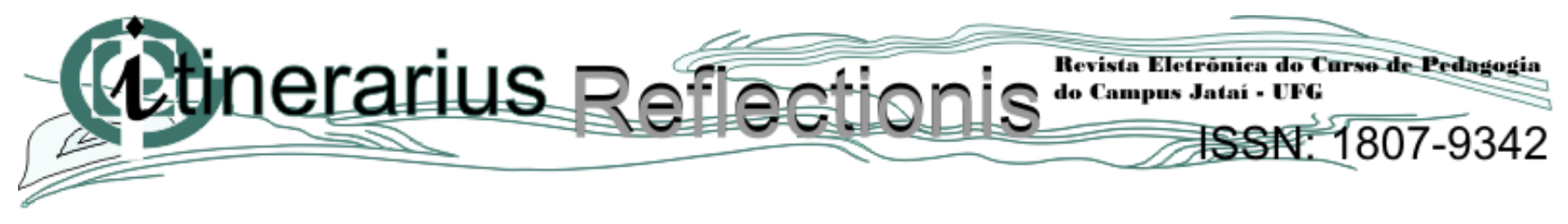

\section{REFERÊNCIAS}

ARAÚJO, M. S. T.; ABIB, M. L. V. S. Atividades Experimentais no Ensino de Física: diferentes enfoques, diferentes finalidades. Revista Brasileira de Ensino de Física, São Paulo, v. 25, n. 2, p. 176-194, jun. 2003. Disponível em: <http://www.seer.ufrgs.br/index.php/InfEducTeoriaPratica/article/viewFile/2397/1742>Acesso em: 28/11/2008.

ARROIO, Agnaldo et al. O Show da Química: Motivando o Interesse Científico. Química Nova, 29 (1), 173-178, 2006.

ARRUDA, S. M.; LABURU, C. E. Considerações sobre a função do experimento no ensinode ciências. In: NARDI, R. Educação em ciências da pesquisa à prática docente, 3. São Paulo:Escrituras, 2001. p. 53-60.

CARDOSO, Sheila Presentin \& COLINVAUX, Dominique. Explorando a Motivação para Estudar Química. Química Nova, 23 (2), 2000.

DEMO, P. . A Nova LDB - Ranços e avanços. In: Maria Neusa de Oliveira. (Org.). As Políticas Educacionais no Contexto da Globalização. 1 ed. Ilhéus: Editus (Editora da UESC), 1999, v. 1, p. 1940.Diretrizes Operacionais da Rede Pública Estadual de Ensino de Goiás 2011/2012. Disponível em : <http://www.educacao.go.gov.br/documentos/Diretrizes2011.pdf> acesso em: 30 de ago de 2013.

GIOR DAN, M. O Papel da Experimentação no Ensino de Ciências. Química Nova naEscola, no.10, p. 43 49, 1999.

GIORDAN, M. Experimentação por simulação. Textos LAPEQ, USP, São Paulo, n. 8, junho 2003.

GIOPPO, C.; SCHEFFER, E.W.O; NEVES, M.C.D. O ensino experimental na escola fundamental: uma reflexão de caso no Paraná. Educar, n.14, 1999. p.39-57. 


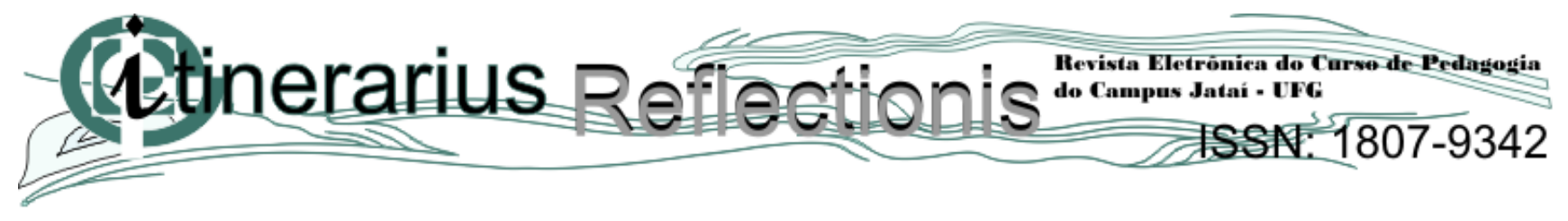

LIMA, V. A. de. Atividades Experimentais no ensino médio: reflexão de um grupo de professores a partir do tema eletroquímica. (Dissertação de Mestrado) - USP: São Paulo. 2004.

LIMA, S. L. et al. Aspectos Didáticos e Implicações do Uso de Aulas Demonstrativas de Química. Trabalho apresentado ANNQ. Disponível em <www.annq.org/congresso2007>. Acesso em 25/06/08.

LIMA, V. e MARCONDES, M.E. Atividades Experimentais no Ensino de Química: Reflexões de um grupo de professores a partir do tema eletroquímica. Ensenañza de Las Ciencias, 2005. Número Extra. VII CONGRESO. Disponível em http://ensciencias.uab.es/congres2005/material/comuni_orales/3_Relacion_invest/3_2/alves_649.pdf

MACHADO, P. F. L.; MÓL, G. de S. Experimentando química com segurança. Revista Química Nova na Escola, São Paulo, n. 27, p.57-60, fev. 2008.

MESQUITA, K. F. M. \& MEDEIROS, T. J. M. M.. Alternativas Didáticas para Aulas de Química no Nível Médio. XLVI Congresso Brasileiro de Química. Salvador: 2006.

PERRENOUD, P.1999. Construir as competências desde a escola. Editora Artmed: Porto Alegre, 89p.

PERRENOUD, P. 2000.0 que fazer da ambigüidade? Revista Pátio, ano 6, n. 23, p.8-11.

PERRENOUD, P. 2000. Pedagogia diferenciada: das intenções a ação. Editora Artmed: Porto Alegre, p. 183.

PERRENOUD, P; THURLER, M. G; MACEDO, L; MACHADO, N. J; ALLESSANDRINI, C. D. 2002. As competências para ensinar no século XXI: a formação dos professores e o desafio da avaliação. Editora Artmed: Porto Alegre, 176p. 


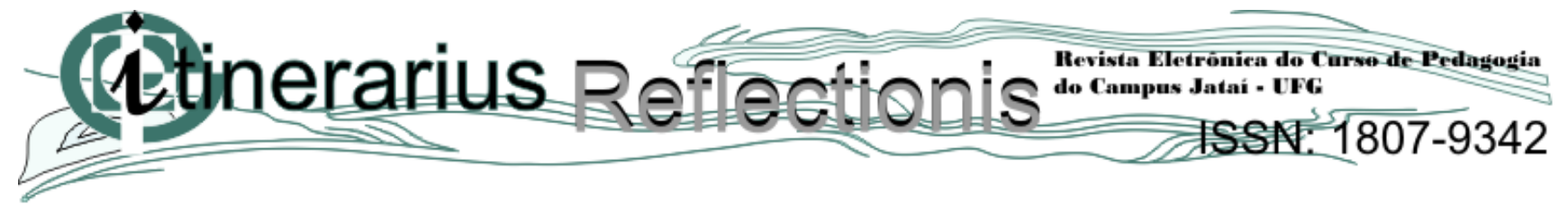

SANTOS, W. L. P.; SCHNETZLER, R. P. Função Social: o que significa ensino de química para formar cidadão? Química Nova na Escola, n.4, nov. 1996.

SANTOS, W. L. P. e SCHNETZLER, R. P. Educação em química: Compromisso com a cidadania. 3.ed.Ijuí, 2003.

SANTOS, Daniel de O.; SANTANA, Rafael de Jesus; ANDRADE, Djalma; LIMA, Patrícia S. de. Experimentação: contribuições para o processo de ensino aprendizagem do conteúdo de Cinética Química. 30 Reunião Anual da Sociedade Brasileira de Química: 2004.

SILVA, Sônia Aparecida de Moreira \& OLIVEIRA, André Luís de. A música no ensino de ciências: perspectivas para a compreensão da ecologia e a temática CTSA (Ciência, Tecnologia, Sociedade e Ambiente. Paraná: 2008.

\section{Anexos}

\section{ANEXO 1}

\section{CLASSIFICAÇÃO DAS REAÇÕES: ADIÇÃO E DECOMPOSIÇÃO}

\section{Introdução:}

Quando misturam duas substâncias nem sempre ocorrem reações químicas, pois são necessárias certas condições permitindo fazer previsões sobre a ocorrência ou não de determinada reação. Nessa aula prática, trabalharemos apenas com as reações de adição e decomposição:

\section{Síntese ou adição}

Nesta reação, dois ou mais reagentes (A e B) se combinam, formando apenas um produto (AB).

$$
\mathrm{A}+\mathrm{B} \rightarrow \mathrm{AB}
$$

\section{Análise ou decomposição}

É a reação em que apenas um reagente $(\mathrm{AB})$ produz dois ou mais produtos (A e B).

$$
\mathrm{AB} \rightarrow \mathrm{A}+\mathrm{B}
$$

\section{Material necessário:}


- Dicromato de amônio

- Magnésio

- Fósforo vidro de relógio

- Pinça de metal.

\section{Objetivos:}

- Analisar a classificação das reações químicas (adição e decomposição ) por meio de uma prática.

\section{Dinâmica:}

- Formar grupos de no máximo 5 alunos por bancada, analisar a experiência que será realizada pelo professor. Em seguida responder as questões abaixo.

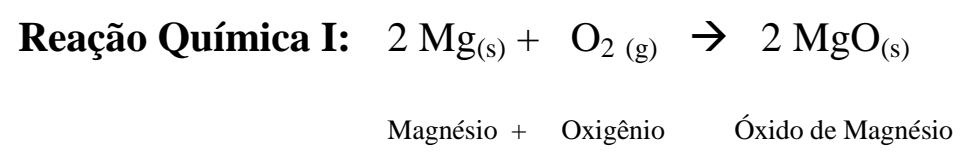
Reação Química II: $\left(\mathrm{NH}_{4}\right)_{2} \mathrm{Cr}_{2} \mathrm{O}_{7(\mathrm{~s})} \rightarrow \mathrm{Cr}_{2} \mathrm{O}_{3(\mathrm{~s})}+\mathrm{N}_{2(\mathrm{~g})}+4 \mathrm{H}_{2} \mathrm{O}_{(\mathrm{v})}$ Dicromato de amônio Óxido de cromo(III) Gás nitrogênio Água

\section{Procedimento experimental:}

1. Coloca um vidro de relógio dicromato de amónio adiciona aparas de magnésio.

2. De seguida, fornece-lhe energia, chegando um fósforo ao centro. Espera que a reação ocorra.

Questões: Estas questões devem ser entregues pelo grupo até o término da aula.

1. Quais os conceitos e conteúdos de química e/ou ciências podem ser explorados com esta atividade.

2. Dê o nome das reações químicas (classificação) envolvidas na experiência.

3. Qual foi a relevância no seu aprendizado ao realizar esta experiência?

4. Em sua opinião, aulas práticas que envolvam a teoria trabalhada em sala de aula desenvolvem melhor o seu conhecimento de química?
( ) Sim
( ) Não
Justifique: 


\section{ANEXO 2}

\section{CLASSIFICAÇÃO DAS REAÇÕES: SIMPLES TROCA E DUPLA-TROCA}

\section{Introdução:}

Quando misturam-se duas substâncias nem sempre ocorrem reações químicas, pois são necessárias certas condições permitindo fazer previsões sobre a ocorrência ou não de determinada reação. Nessa aula prática, trabalharemos apenas com as reações de simples troca ou deslocamento e dupla-troca:

\section{Simples troca ou deslocamento}

É a reação em que uma substância simples se combina com uma substância composta, formando outra substância simples e outra composta.

$$
\mathrm{AB}+\mathrm{C} \rightarrow \mathrm{AC}+\mathrm{B} \quad \text { ou } \quad \mathrm{AB}+\mathrm{C} \rightarrow \mathrm{CB}+\mathrm{A}
$$

\section{Dupla troca ou permutação}

Neste tipo de reação ocorre uma troca entre duas substâncias compostas que se combinam, formando duas outras substâncias compostas.

$$
\mathrm{AB}+\mathrm{CD} \rightarrow \mathrm{AD}+\mathrm{CB}
$$

\section{Material necessário:}

- Ferro metálico

- Ácido clorídrico (ácido muriático)

- Nitrato de prata,

- Cloreto de sódio (solução)

- Tubos de ensaio

\section{Objetivos:}

- Analisar a classificação das reações químicas por meio de uma aula prática;

- Balancear as equações das reações químicas

\section{Dinâmica:}


- Formar grupos de no máximo 5 alunos por bancada, realizar a aula prática. Em seguida responder as questões abaixo.

Reação Química I: $\mathrm{Fe}_{(\mathrm{s})}+\mathrm{HCl}_{(\mathrm{aq})} \rightarrow \mathrm{FeCl}_{3(\mathrm{aq})}+\mathrm{H}_{2(\mathrm{~g})}$

$$
\text { Ferro Ácido Clorídrico Cloreto de Ferro III Gás Hidrogênio }
$$

Reação Química II: $\quad \underset{\text { Nitrato de Prata }}{\mathrm{AgNO}_{3}}(\underline{\mathrm{aq}})+\underset{\text { Cloreto de Sódio }}{\underline{\mathrm{NaCl}}(\mathrm{aq})} \rightarrow \quad \underline{\underline{\mathrm{AgCl}}(\underline{\mathrm{s}})+}+\frac{\underline{\mathrm{NaNO}}_{3}(\mathrm{aq})}{\text { Cloreto de Prata }}$

\section{Procedimento experimental:}

\section{Reação Química I:}

- Escolha um tubo de ensaio e adicione uma pequena quantidade de Ferro (Fe);

- Adicione uma pequena quantidade de Ácido Clorídrico $(\mathrm{HCl})$ com muito cuidado;

- Observe o que aconteceu e anote.

\section{Reação Química II:}

- Escolha um tubo de ensaio e adicione 5 gotas da solução de Nitrato de Prata $\left(\underline{A g N O}_{3}\right)$ com muito cuidado;

- Adicione uma pequena quantidade de solução de Cloreto de Sódio $(\mathrm{NaCl})$;

- Observe o que aconteceu e anote.

Questões: Estas questões devem ser entregues pelo grupo até o término da aula.

1. Dê o nome das reações químicas (classificação) envolvidas na experiência.

2. O ser humano em seu cotidiano pode se deparar com vários tipos de reações químicas. Um tipo de reação inorgânica muito importante em nosso cotidiano é a reação de simples troca, ou de deslocamento, ou ainda, de substituição, no qual ocorrem quando uma substância simples reage com uma substância composta, originando uma nova substância simples e outra composta. Ocorre uma troca de seus elementos ligantes, daí a origem de seu nome. Diante disso, responda: 


\section{(5tinerarius Refilectionis $=$}

O que são substâncias simples e compostas? Justifique com exemplos.

3. Em uma equação química, o balanceamento tem um papel fundamental, pois consiste em igualar o número de elementos do produto com os reagentes. Sendo assim, verifique o balanceamento das equações químicas acima, e faça o balanceamento se for necessário.

4. Ao analisar a reação de dupla troca ou reação de metátese (reação onde há dois reagentes, ambos compostos gerando dois produtos, sendo que são igualmente dois compostos, permutando entre si dois elementos ou radicais) realizada durante a aula prática, descreva o seu produto final.

5. A experimentação é a atividade didático-pedagógica que mais desperta o interesse e a curiosidade dos aprendizes. Você concorda com essa afirmação? Justifique sua resposta.
( ) SIM
( ) NÃO 